Article

\title{
The Graphene/L-Cysteine/Gold-Modified Electrode for the Differential Pulse Stripping Voltammetry Detection of Trace Levels of Cadmium
}

\author{
Yu Song ${ }^{1,2}$, Chao Bian ${ }^{1, *}$, Jianhua Tong ${ }^{1}$, Yang $\mathrm{Li}^{1}$ and Shanghong Xia ${ }^{1, *}$ \\ 1 State Key Laboratory of Transducer Technology, Institute of Electronics Chinese Academy of Sciences, \\ Beijing 100190, China; songyu1990@126.com (Y.S.); jhtong@mail.ie.ac.cn (J.T.); yangli@mail.ie.ac.cn (Y.L.) \\ 2 University of Chinese Academy of Sciences, Beijing 100190, China \\ * Correspondence: cbian@mail.ie.ac.cn (C.B.); shxia@mail.ie.ac.cn (S.X.); Tel.: +86-10-5888-7187 (C.B.); \\ $+86-10-5888-7180$ (S.X.)
}

Academic Editor: Hiroshi Mizuta

Received: 24 March 2016; Accepted: 6 June 2016; Published: 13 June 2016

\begin{abstract}
Cadmium(II) is a common water pollutant with high toxicity. It is of significant importance for detecting aqueous contaminants accurately, as these contaminants are harmful to human health and environment. This paper describes the fabrication, characterization, and application of an environment-friendly graphene (Gr)/L-cysteine/gold electrode to detect trace levels of cadmium (Cd) by differential pulse stripping voltammetry (DPSV). The influence of hydrogen overflow was decreased and the current response was enhanced because the modified graphene extended the potential range of the electrode. The Gr/L-cysteine/gold electrode showed high electrochemical conductivity, producing a marked increase in anodic peak currents (vs. the glass carbon electrode (GCE) and boron-doped diamond (BDD) electrode). The calculated detection limits are 1.15, 0.30 , and $1.42 \mu \mathrm{g} / \mathrm{L}$, and the sensitivities go up to $0.18,21.69$, and $152.0 \mathrm{nA} \cdot \mathrm{mm}^{-2} \cdot \mathrm{\mu g}^{-1} \cdot \mathrm{L}$ for, respectively, the BDD electrode, the GCE, and the Gr/L-cysteine/gold electrode. It was shown that the Gr/L-cysteine/gold-modified electrode is an effective means for obtaining highly selective and sensitive electrodes to detect trace levels of cadmium.
\end{abstract}

Keywords: graphene/L-cysteine/gold electrode; glass carbon electrode; boron-doped diamond electrode; differential pulse stripping voltammetry; cadmium

\section{Introduction}

Cadmium (Cd) has long been recognized as one of the most notable toxic heavy metals to ecosystems and human health $[1,2]$. It was used widely as an anticorrosive layer when electroplated onto steel, and cadmium compounds are used in batteries and as pigments. Cadmium and its compounds are of concern among main aqueous elements due to their high toxicity to aquatic organisms and their environments [3]. Accumulation of $\mathrm{Cd}$ can lead to severe chemical pneumonitis, lung cancer, and renal tubular dysfunction. Even the intake of trace levels of cadmium can lead to acute or chronic health issues such as kidney toxicity, cancer, and bone demineralization [4]. Therefore, the global urgency of on-site monitor, which can detect trace Cd(II) rapidly, sensitively, and reliably, has been increasingly underscored [5].

Conventional spectrometric measurements for metals include atomic absorption spectrophotometry (AAS) [6-8], inductively coupled plasma mass spectrometry (ICP-MS) [9,10], inductively coupled plasma atomic emission spectroscopy (ICP-AES) [11,12], atomic absorption spectrometry [13], and atomic fluorescence spectroscopy [14]. Complicated operations, costly instrumentation, and a long sample processing time limit the on-site application of these methods. A simple, low-cost, and user-friendly analytical method for on-site analysis is favored in cadmium 
detection. Electrochemical sensors provide promising approaches to monitor fresh water because of their simplicity and high sensitivity especially when differential pulse stripping voltammetry is applied. The traditional electrode for electrochemical detection of heavy metals has an imperfection that mercury is used and would bring about contamination [15]. Therefore, it is important to develop methods for environment-friendly efficient detection of $\mathrm{Cd}$ in aqueous solutions, especially at trace levels.

To address this issue, several nanoparticles have been modified on the surface of electrode based on nanotechnology, which has demonstrated exciting prospects in both chemical and optical determination of $\mathrm{Cd}(\mathrm{II})$ over the past decades. A variety of electrode surface modifications have been explored to increase sensitivity for metal detection. Sensitive, environment-friendly, and efficient determinations of heavy metal have been developed by grafting various kinds of nanomaterials onto the surface of electrodes. Platinum and gold electrodes in different forms and sizes have been widely used as backing material in electrochemical analysis due to their excellent electron transfer kinetics. However, they have been limited to detection in a positive potential range for most heavy metals due to the low hydrogen overvoltage that reduces the cathodic potential window, while the stripping peak of cadmium is comparatively negative. Platinum and gold electrodes can be combined with various nanoparticles and have a wide potential range.

Carbon-based electrodes, such as the glass carbon electrode (GCE), the boron-doped diamond (BDD) electrode, and the graphene-modified electrode, have a wide working potential range to make extensive analyses, low background currents to obtain high sensitivity, and stable structures to overcome harsh chemical environments. Graphene, a new type of environmental film, has also shown high hydrogen overpotential, which can suppress the hydrogen overflow on a gold electrode. Graphene is a 2D nanomaterial of $\mathrm{sp}^{2}$-bonded carbon atoms [16,17]. Moreover, graphene can be activated or connected by covalent bonding with glass carbon electrodes, and the modified electrodes retain graphene physical properties and chemical tenability including a high surface-to-volume ratio, a large active surface area, and an exceptional electrical property [18,19]. Since graphene formed by chemical activation possesses high electron transfer promoting ability [20] and excellent catalytic behavior, it has been widely used in novel chemical sensors on glassy carbon electrodes (GCEs) [21-25].

In this paper, graphene was modified on a gold electrode via a self-assembled method based on thiols and related molecules, which provided a way to perform $\mathrm{Cd}$ detection in a negative potential range [16]. We tried to combine carboxylic graphene (GN-COOH) with a gold electrode via thiol compound covalent bonding due to the function group hydroxyl $(-\mathrm{OH})$ in the basal plane of carboxylic graphene and the amino-group in the gold electrode [26,27]. L-cysteine was selected as the linker between graphene and gold microelectrode as it provides fast electron transfer for electrochemical detection and amino group that can potentially join with graphene by dehydration-condensation reaction. The boron-doped diamond (BDD) electrode and the glass carbon electrode (GCE) were also examined for $\mathrm{Cd}$ measurements, and the results were compared with that of the Gr/L-cys/Au electrode.

\section{Materials and Methods}

\subsection{Apparatus and Reagents}

The purities of all reagents were in analytical grade except those stated separately. Double distilled water $(18 \mathrm{M} \Omega \cdot \mathrm{cm})$ was used to prepare for samples. Cadmium standard stock solution $(100 \mathrm{mg} / \mathrm{L}$ $\mathrm{Cd}^{2+}$ in 3\% nitric acid) was purchased from the China National Research Centre for Certified Reference Material. Cadmium samples were carefully diluted from the stock solution with double-distilled water. Carboxyl graphene ( $2 \mathrm{mg} / \mathrm{L}$ ) was from Nanjing XFNANO Materials Tech Co., Ltd. (Nanjing, China). Dichloroethane (EDC) and N-Hydroxysuccinimide (NHS) were purchased from Sigma-Aldrich (St. Louis, MO, USA). Sodium acetate and glacial acetic acid were obtained from Xilong Tech Co., Ltd. (Shantou, China). Ferricyanide solution $(0.5 \mathrm{mM})$ was added into $0.1 \mathrm{M} \mathrm{KCl}$ solution. 
Electrochemical tests were conducted by Gamry Reference 600 electrochemical workstation (Gamry Instruments Co., Ltd., Warminster, PA, USA) using a three-electrode system based on a microelectrode chip. For comparison, traditional electrochemical bulk electrodes were used, while the glassy carbon electrode and the boron-doped diamond electrode ( $3 \mathrm{~mm}$ in diameter) served as the working electrode, the platinum disk electrode ( $3 \mathrm{~mm}$ in diameter) served as a counter electrode, and $\mathrm{Ag} / \mathrm{AgCl}$ (saturated $\mathrm{KCl}$ ) served as the reference electrode.

Field-emission scanning electron microscope (FE-SEM; S-4800) produced by Hitachi (Hitachi, Japan) was used to check the morphologies of the graphene.

\subsection{Fabrication and Modification of Microelectrode Chip}

The ring-disk microelectrode chip contains a gold working microelectrode, a platinium counter electrode. The microelectrode was prepared by the MEMS technique. The gold-working electrode was fabricated by standard optical lithography and a lift-off process with a diameter of $3 \mathrm{~mm}$. Before modification, the gold microelectrode was cleaned in $0.01 \mathrm{M} \mathrm{H}_{2} \mathrm{SO}_{4}$ until a stable curve was obtained. The gold microelectrode was dipped in $20 \mu \mathrm{L}$ of $10 \mathrm{mM} \mathrm{L}$-cysteine $\left(\mathrm{C}_{2} \mathrm{H}_{7} \mathrm{NS}\right)$ solution for $6 \mathrm{~h}$ at $4{ }^{\circ} \mathrm{C}$. The L-cysteine-modified gold electrode was obtained after $6 \mathrm{~h}$ of immersion. The modified gold microelectrode was washed with deionized water and dried in air for $24 \mathrm{~h}$. Then, a mixed solution of NHS and EDC was applied into the carboxyl graphene (GN-COOH) solution for 15 min at $4{ }^{\circ} \mathrm{C}$. Three microliters of the graphene-mixed solution was dispensed on the surface of the L-cysteine-modified gold microelectrode for $12 \mathrm{~h}$ at $25^{\circ} \mathrm{C}$. The hydroxyl group of the GN-COOH bond with the amino group of L-cysteine on the Au microelectrode with those steps. Finally, the carboxyl graphene (GN-COOH)-modified gold microelectrode was modified with L-cysteine as shown in Figure 1.

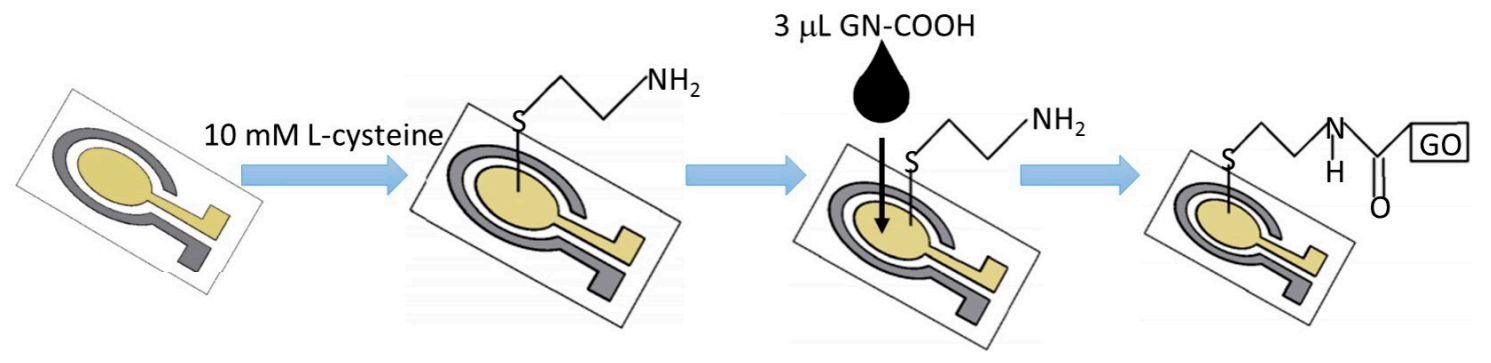

Figure 1. Schematic drawing of the Gr/L-cysteine nanocomposite self-assembly process.

\subsection{Electrochemical Methods of Differential Pulse Stripping Voltammetry (DPSV)}

Differential pulse stripping voltammetry (DPSV) was applied to detect trace levels of cadmium under an optimized condition. All solutions were stored in a 20-mL Teflon bottle. DPSV parameters were optimized such that cadmium was deposited for $360 \mathrm{~s}$ at $-1.1 \mathrm{~V}$ in $0.1 \mathrm{M}$ acetate buffer ( $\mathrm{pH} 4.50)$. The DPSV of electrodeposit metal was performed in the potential range of -1.1 to $0.5 \mathrm{~V}$. The samples were homogeneous medium via stirring during the deposition steps, and the magnetic stirrer turned off for $120 \mathrm{~s}$ to equipoise prior to the DPSV scan.

\section{Discussion}

\subsection{Characterization of Microelectrode Chip}

The typical SEM images of Gr/L-cysteine/Au electrode are shown in Figure 2. The morphology of the $\mathrm{GN}-\mathrm{COOH} / \mathrm{L}$-cysteine composite is rougher and sheets of graphene are clear in the edge of electrode. There are some thin folds on the surface in the center of the electrode. The electrochemical properties of different gold electrodes were characterized by CV. Figure 3a shows the voltammetric response of bare $\mathrm{Au}, \mathrm{L}$-cys/Au, Gr/L-cys/Au, and Gr/L-cys/Au electrodes in solution containing 
$0.5 \mathrm{mM} \mathrm{Fe}(\mathrm{CN})_{3}{ }^{3-}$ and $0.1 \mathrm{M} \mathrm{KCl}$. Compared with the $\mathrm{CV}$ curve of the bare gold electrode (curve a), an obviously increased redox current was obtained by the L-cysteine-modified gold electrode (curve b). After the chemical bond between GN-COOH and L-cysteine layer, the redox current of $\mathrm{Gr} / \mathrm{L}$-cysteine/Au electrode (curve c) decreases compared with the L-cysteine/Au electrode. It can be seen from the reduced redox current that electron transfer was inhibited by the graphene layer. Reduction of GN-COOH to $\mathrm{rGN}-\mathrm{COOH}$ (curve d) increases the conductivity of the catalyst. The existence of $\mathrm{rGN}-\mathrm{COOH}$ results in a stronger combination of cadmium with the modified electrode. The subsequent stripping of cadmium was therefore kinetically harder, and the stripping potential became more negative. However, this potential shift brings about fierce hydrogen evolution, which may damage the deposition layer. Consequently, the rG/L-cys/Au electrode cannot be applied to Cd detection.

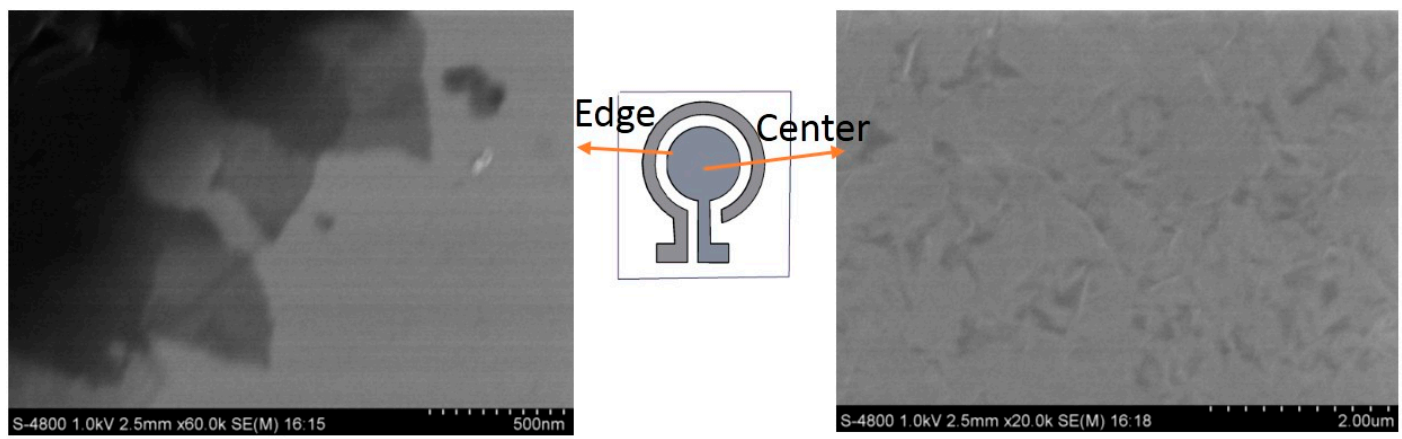

Figure 2. SEM of the center and edge of Gr/L-cysteine/Au electrode.
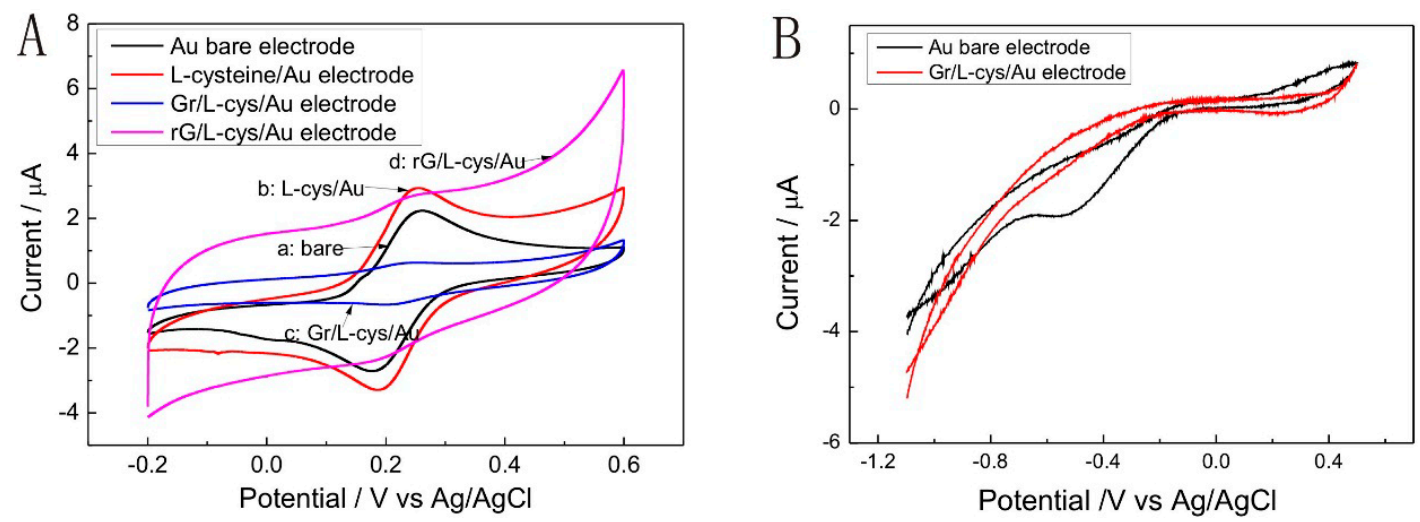

Figure 3. (A) Cyclic voltammograms of bare $\mathrm{Au}$, L-cysteine/Au, Gr/L-cys/Au, and rG/L-cys/Au electrode in solution containing $0.5 \mathrm{mM}$ ferri/ferrocyanide and $0.1 \mathrm{M} \mathrm{KCl}$; (B) Cyclic voltammograms between -1.1-0.5 $\mathrm{V}$ of $\mathrm{H}_{2} \mathrm{SO}_{4}, \mathrm{pH} 4.50$, at an Au bare electrode and $\mathrm{Gr}$ / L-cys/Au electrode.

The influence of oxygen on the voltammetric behaviors of the bare gold electrode and the $\mathrm{Gr} / \mathrm{L}-\mathrm{cys} / \mathrm{Au}$ on the surface is shown in Figure 3b. The cyclic voltammogram (CV) shows one reduction peak on the bare gold electrode at $-0.5 \mathrm{~V}$. Generally, the reduction peak was a two-electron reduction of $\mathrm{O}_{2}$ to $\mathrm{H}_{2} \mathrm{O}_{2}$ at the gold surface depending on the $\mathrm{pH}$ of the medium, which easily occurred in acidic media [28]. It can be seen that no significant reduction peak occurred at Gr/L-cys/Au electrode. Such behavior was due to the fabrication of graphene on the gold electrode and the graphene-modified gold electrode can be used in cadmium determination.

\subsection{Optimazation of Depositon Time and $p H$ Value of Detection Solution}

In order to investigate the influence of the deposition time and $\mathrm{pH}$ value of the detection solution, experiments were designed with $10 \mu \mathrm{g} / \mathrm{L} \mathrm{Cd}$ (II) by DPSV to identify the current response on the 
Gr/L-cys/Au electrode. As the pre-concentration time increased from 120 to $840 \mathrm{~s}$, the peak currents for $\mathrm{Cd}^{2+}$ at $\mathrm{pH} 4.50$ linearly increased, owing to the increased amount of cadmium ion on the Gr/L-cys/Au electrode. However, the stripping currents tended to slightly deviate from the linear region after $360 \mathrm{~s}$, as shown in Figure 4A, due to the saturated loading of the electrode surface. The $\mathrm{pH}$ is another key parameter, which effects the sensitivity. Compared with the current responses at various $\mathrm{pH}$ values, the current response is obviously influenced by $\mathrm{pH}$ and reaches its highest value at $\mathrm{pH} 4.50$ when the deposition time is $360 \mathrm{~s}$ (Figure 4B). For further study, pH 4.50 and $360 \mathrm{~s}$ deposition time were selected for Cd detection via the DPSV method.
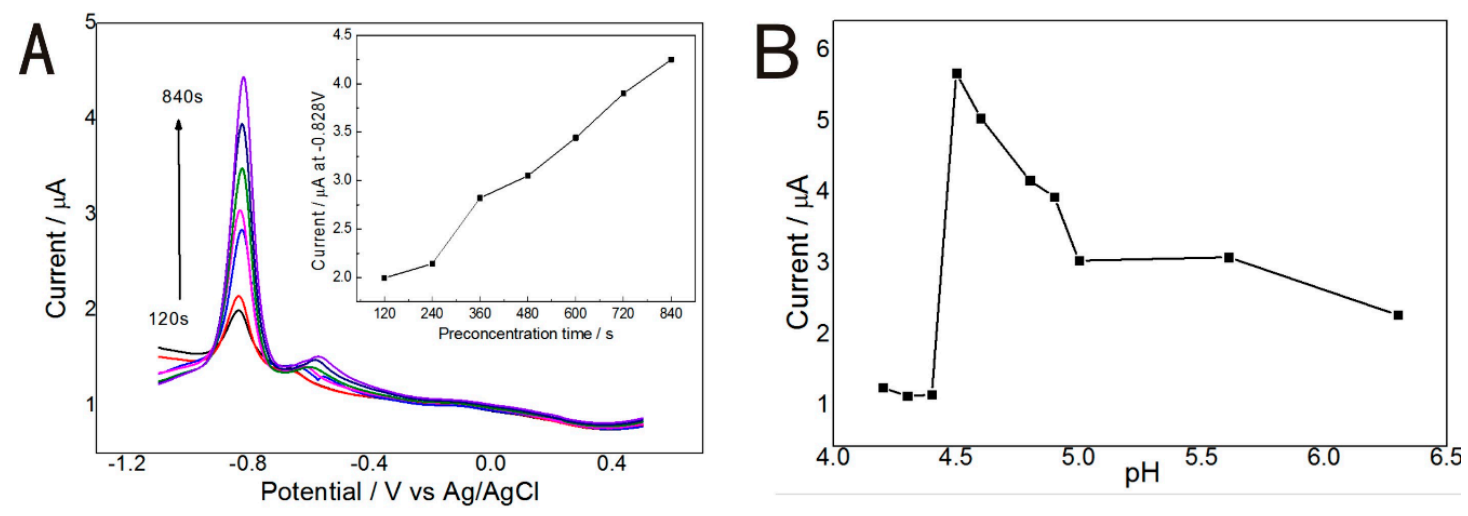

Figure 4. Effect of deposition time (A) on the differential pulse stripping voltammetry (DPSV) peak current of $10 \mu \mathrm{g} / \mathrm{L} \mathrm{Cd}(\mathrm{II})$ at $\mathrm{pH}$ 4.50. Effect of $\mathrm{pH}(\mathbf{B})$ on the DPSV peak current of $10 \mu \mathrm{g} / \mathrm{L} \mathrm{Cd}(\mathrm{II})$ with deposition time of $360 \mathrm{~s}$.

\subsection{Electrochemical Characterization of the Gr/L-Cysteine Composite-Modified Electrode}

The thickness of the one layer was measured by atomic force microscope (AFM). Figure 5 shows its surface morphology of the bare gold (A) and Gr/L-cys / Au (B) electrodes drawn by AFM. The height profile of one layer's is about $120 \mathrm{~nm}$ along the line across the membrane surface. It is believed that $2 \mathrm{D}$ graphene sheets combined to create an interconnected framework. The overlap of graphene can greatly enhance the specific surface area of the Gr/L-cys/Au electrode and can give the unfolded graphene a significant character to capture metal ions during deposition time in aqueous phase [29].
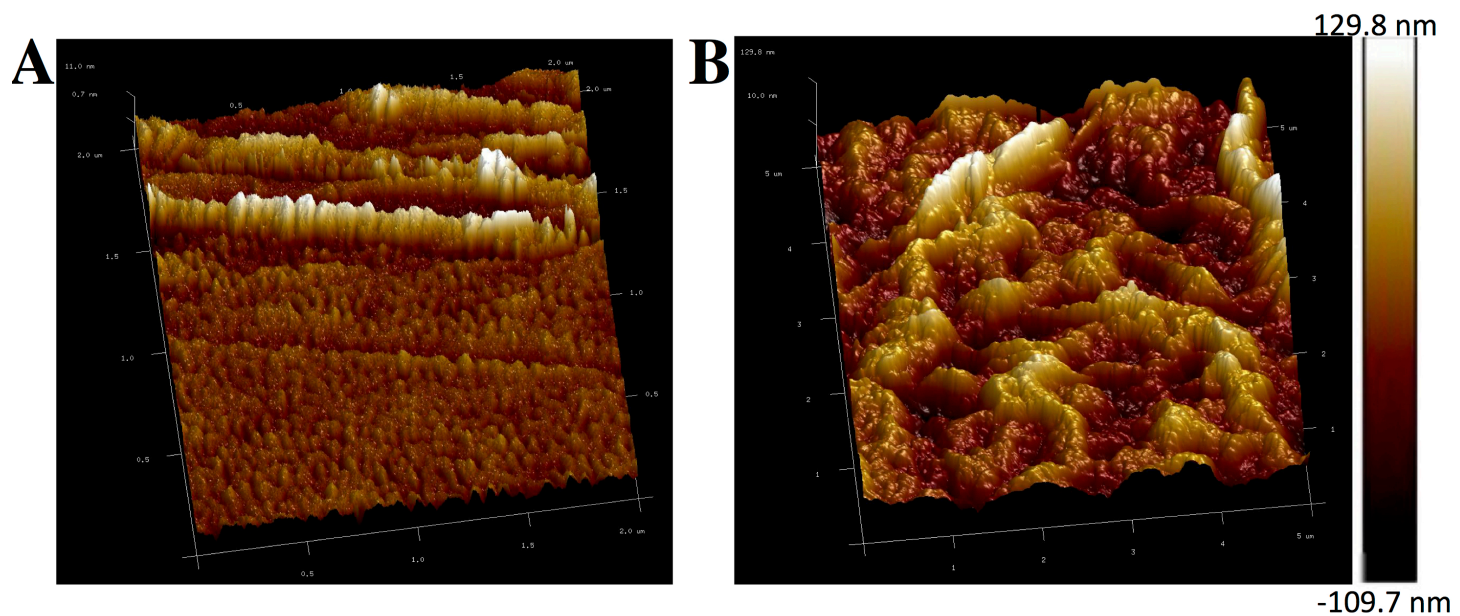

Figure 5. AFM images of bare (A) gold electrode and (B) Gr/L-cys/Au electrode.

Figure 6 illustrates the representation of different self-assembled graphene layers. The number of layers means the times graphene drop-casting is performed. Graphene drop-casting comprises 
two steps: $3 \mu \mathrm{L}$ of prepared GN-COOH solution was drop-casted onto the electrode surface; then, the electrode was air-dried for $12 \mathrm{~h}$. As shown in Figure 6, the Gr/L-cysteine composite-modified electrodes generated improved the electrochemical character in a solution containing $0.5 \mathrm{mM}$ ferri/ferrocyanide and $0.1 \mathrm{M} \mathrm{KCl}$. The redox current decreased when the amount of GN-COOH loading increased from 3 to $9 \mu \mathrm{L}$, indicating that adding more $\mathrm{GN}-\mathrm{COOH}$ to the electrode surface could diminish the electrochemical sensitivity of modified gold electrode. Graphene incorporation into L-cysteine is crucial for improving the electrochemical properties of the composite. One graphene layer displayed the best sensitivity, stability, and firm combination.

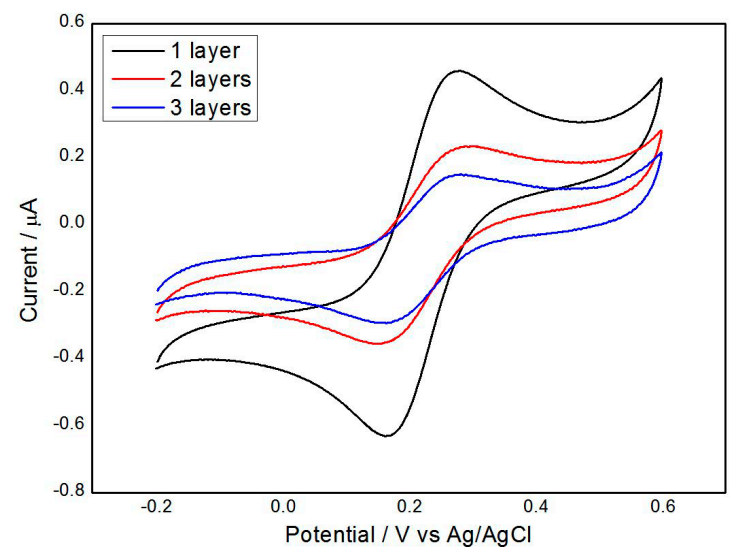

Figure 6. The representation of self-assembled graphene layers of the Gr/L-cysteine/gold microelectrode (all of the microelectrodes diameters were designed to yield $3 \mathrm{~mm}$, and each graphene layer was modified by $3 \mu \mathrm{L}$ of carboxylic graphene).

\subsection{Analytical Performance of the Gr/L-Cys/Au Electrode, the GCE, and the BDD Electrode for Cd(II) Determination}

To detect trace levels of Cd(II), DPSV is used because of its high sensitivity and linearity [30]. To increase electrode sensitivity, L-cysteine was used to connect the electrode surface with the graphene by a self-assembly process. Calibration samples of deionized water (DW) were used to test the analytical performance of our method. Samples were spiked with $0,5,10,15$, and $20 \mu \mathrm{g} / \mathrm{L}$ cadmium(II) from standard stock solutions. The resulting calibration plots are linear over a range from 5 to $20 \mu \mathrm{g} / \mathrm{L}$, with correlation coefficients exceeding 0.95 (Figure 7). The analytical performance of all three electrodes for heavy metal detection (such as cadmium, lead $(\mathrm{Pb})$ ) was also compared with other carbon-based electrode reported previously, which were summarized in Table 1.

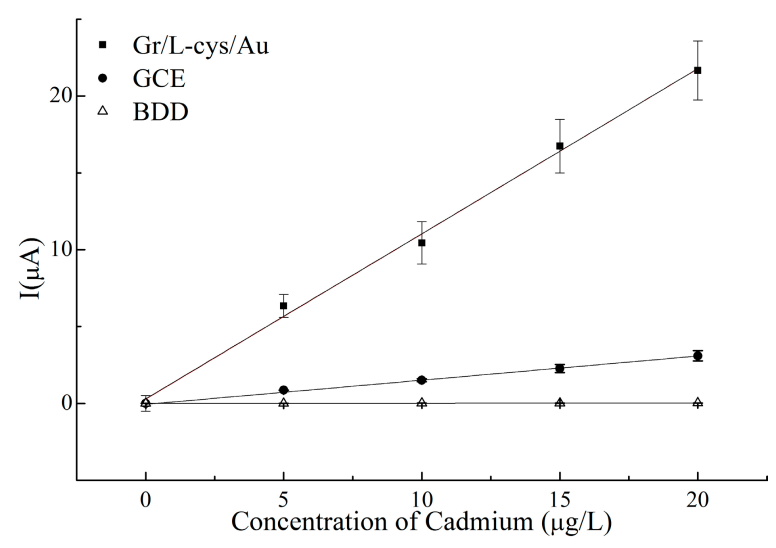

Figure 7. Representative calibration curves of the Gr/L-cys/Au electrode, the GCE, and the BDD electrode by DPSV for the determination of cadmium ions with corresponding error bars $(n=3)$. 
Furthermore, carbon-based electrodes have obtained significant attention in previous reports because of its environmental-friendly effect and high sensitivity, especially the GCE, the BDD electrode, and the graphene [31,32]. A variety of carbon-based electrodes have been experimented with to explore the detection sensitivity of heavy metals. The electrochemical performance of the Gr/L-cysteine nanocomposite-modified gold electrode was compared to the GCE and the BDD electrode in similar systems for measuring trace levels of $\mathrm{Cd}(\mathrm{II})$. Table 1 shows that good linearity is acquired within the 5-20 $\mu \mathrm{g} / \mathrm{L}$ range. The limits of detection (LODs) are determined based on the signal-to-noise ratio at low levels $(\mathrm{S} / \mathrm{N}=3)$ and are $1.42,0.3$, and $1.15 \mu \mathrm{g} / \mathrm{L}$ for the $\mathrm{Gr} / \mathrm{L}$-cys/Au electrode, the glass carbon electrode, and the boron-doped diamond electrode. The sensitivities go up to $0.18,21.69$, and $152.0 \mathrm{nA} \cdot \mathrm{mm}^{-2} \cdot \mu^{-1} \cdot \mathrm{L}$ for, respectively, the BDD electrode, the GCE, and the Gr/L-cys/Au electrode. The sensitivity of the Gr/L-cys/Au electrode was higher than the other carbon-based electrodes, and the detection limit of the proposed method was comparable to other electrochemical detection methods. It was thus shown that the $\mathrm{Gr} / \mathrm{L}$-cys/Au-modified electrode is an effective method for obtaining highly selective and sensitive electrodes for detecting trace levels of cadmium.

Table 1. Electrode performance for measuring heavy metals.

\begin{tabular}{ccccccc}
\hline Electrode & Metal Ion & $\begin{array}{c}\text { Sensitivity } \\
\left(\mathbf{n A} \cdot \mathbf{~ m m}^{-\mathbf{2}} \cdot \boldsymbol{\mu} \mathbf{g}^{-\mathbf{1}} \cdot \mathbf{L}\right)\end{array}$ & $\begin{array}{c}\text { Linearity Range } \\
(\boldsymbol{\mu} \mathbf{g} / \mathbf{L})\end{array}$ & $\begin{array}{c}\text { Correlation } \\
\text { Coefficient }\end{array}$ & LOD $(\boldsymbol{\mu g} / \mathbf{L})$ & Reference \\
\hline Crown/GCE & $\mathrm{Cd}(\mathrm{II})$ & 16 & $7.9-191$ & 0.99 & 2.4 & {$[33]$} \\
MWNTs/GCE & $\mathrm{Cd}(\mathrm{II})$ & 135 & $2.8-110$ & 0.99 & 0.67 & {$[34]$} \\
$\mathrm{N} @ \mathrm{MOG}-\mathrm{C} / \mathrm{GCE}$ & $\mathrm{Cd}(\mathrm{II})$ & 89 & $2.8-55$ & 0.99 & 0.25 & {$[35]$} \\
$\mathrm{b}^{2} \mathrm{SPE}$ & $\mathrm{Pb}(\mathrm{II})$ & 60 & $5-110$ & 0.99 & 1.10 & {$[36]$} \\
GCE & $\mathrm{Cd}(\mathrm{II})$ & 21.69 & $5-20$ & 0.998 & 0.30 & This work \\
BDD & $\mathrm{Cd}(\mathrm{II})$ & 0.18 & $5-20$ & 0.950 & 1.15 & This work \\
Gr/L-cys/Au & $\mathrm{Cd}(\mathrm{II})$ & 152.0 & $5-20$ & 0.997 & 1.42 & This work \\
\hline
\end{tabular}

MWNTs: multi-wall carbon nanotubes; N@MOG-C: nitrogen-doped porous carbon material; $\mathrm{b}^{2} \mathrm{SPE}$ : back-to-back screen-printed electrode.

\section{Conclusions}

In this work, the gold disk microelectrodes with the sensing diameter of $3 \mathrm{~mm}$ were fabricated by the MEMS technique on a glass wafer. The novel Gr/L-cysteine film was successfully modified on gold microelectrode, and the structure of the microelectrode chip demonstrated the fabrication of this composite electrode. The Gr/L-cysteine/gold electrode showed microelectrode behavior and yielded a high, steady current. The electrochemical characteristics of the microelectrode during modifications were investigated by cyclic voltammetry in [34]. The representation of a different self-assembled graphene layer suggests that one graphene layer is very secure and achieves better sensitivity. The effects of deposition time and $\mathrm{pH}$ on the DPSV peak current were investigated. The calibration plots of the Gr/L-cysteine gold microelectrode, the GCE, and BDD electrode for Cd(II) determination are linear with a range from 5 to $20 \mu \mathrm{g} / \mathrm{L}$, with correlation coefficients exceeding 0.95 . The Gr/L-cysteine gold microelectrode showed the highest sensitivity compared with the bare glassy carbon and boron-doped diamond due to the use of graphene and microelectrodes. In addition to the present work, this modified microelectrode can also be used for the detection of other trace metals that have lower deposition potentials than cadmium.

Acknowledgments: The authors express their deep gratitude to the staff at the State Key Laboratory of Transducers Technology at the Institute of Electronics, Chinese Academy of Sciences for a clean room and micro-fabrication support. We acknowledge financial support from the National Program on Key Basic Research Project (973 Program, No. 2015CB352100).

Author Contributions: All authors conceived and designed the experiments; Yu Song performed the experiments; Yu Song, Yang Li and Chao Bian analyzed the data; Jianhua Tong and Shanhong Xia contributed reagents/materials/analysis tools; Shanhong Xia and Chao Bian are equally contributing corresponding authors.

Conflicts of Interest: The authors declare no conflict of interest. The founding sponsors had no role in the design of the study; in the collection, analyses, or interpretation of data; in the writing of the manuscript, and in the decision to publish the results. 


\section{Abbreviations}

The following abbreviations are used in this manuscript:

$\begin{array}{ll}\text { Cd } & \text { cadmium } \\ \text { Gr } & \text { graphene } \\ \text { L-cys } & \text { L-cysteine } \\ \text { GCE } & \text { glass carbon electrode } \\ \text { BDD } & \text { boron-doped diamond } \\ \text { DPSV } & \text { differential pulse stripping voltammetry }\end{array}$

\section{References}

1. Zang, Y. Cadmium: Toxicology. In Encyclopedia of Food and Health; Caballero, B., Finglas, P.M., Toldrá, F., Eds.; Academic Press: Oxford, UK, 2016; pp. 550-555.

2. Kovacik, J.; Klejdus, B.; Hedbavny, J.; Stork, F.; Backor, M. Comparison of cadmium and copper effect on phenolic metabolism, mineral nutrients and stress-related parameters in Matricaria chamomilla plants. Plant Soil 2009, 320, 231-242. [CrossRef]

3. Zahir, F.; Rizwi, S.J.; Haq, S.K.; Khan, R.H. Low dose mercury toxicity and human health. Environ. Toxicol. Pharmacol. 2005, 20, 351-360. [CrossRef] [PubMed]

4. Van Maele-Fabry, G.; Lombaert, N.; Lison, D. Dietary exposure to cadmium and risk of breast cancer in postmenopausal women: A systematic review and meta-analysis. Environ. Int. 2016, 86, 1-13. [CrossRef] [PubMed]

5. Gumpu, M.B.; Sethuraman, S.; Krishnan, U.M.; Rayappan, J.B.B. A review on detection of heavy metal ions in water-An electrochemical approach. Sens. Actuators B Chem. 2015, 213, 515-533. [CrossRef]

6. D'Agostino, F.; Oliveri, E.; Bagnato, E.; Falco, F.; Mazzola, S.; Sprovieri, M. Direct determination of total mercury in phosphate rock using alkaline fusion digestion. Anal. Chim. Acta 2014, 852, 8-12. [CrossRef] [PubMed]

7. Olsen, S.; Pessenda, L.C.R.; Ruzicka, J.; Hansen, E.H. Combination of flow-injection analysis with flame atomic-absorption spectrophotometry-Determination of trace amounts of heavy-metals in polluted seawater. Analyst 1983, 108, 905-917. [CrossRef]

8. Ghaedi, M.; Shokrollahi, A.; Kianfar, A.H.; Mirsadeghi, A.S.; Pourfarokhi, A.; Soylak, M. The determination of some heavy metals in food samples by flame atomic absorption spectrometry after their separation-preconcentration on bis salicyl aldehyde, 1,3 propan diimine (BSPDI) loaded on activated carbon. J. Hazard. Mater. 2008, 154, 128-134. [CrossRef] [PubMed]

9. Kot, A.; Namiesnik, J. The role of speciation in analytical chemistry. TrAC Trends Anal. Chem. 2000, 19, 69-79. [CrossRef]

10. Yuan, C.G.; Shi, J.B.; He, B.; Liu, J.F.; Liang, L.N.; Jiang, G.B. Speciation of heavy metals in marine sediments from the East China sea by ICP-MS with sequential extraction. Environ. Int. 2004, 30, 769-783. [CrossRef] [PubMed]

11. Zougagh, M.; de Torres, A.G.A.; Cano Pavón, J.M. Determination of cadmium in water by ICP-AES with on-line adsorption preconcentration using DPTH-gel and TS-gel microcolumns. Talanta 2002, 56, 753-761. [CrossRef]

12. Daskalova, N.; Boevski, I. Spectral interferences in the determination of trace elements in environmental materials by inductively coupled plasma atomic emission spectrometry. Spectrochim. Acta Part B At. Spectrosc. 1999, 54, 1099-1122. [CrossRef]

13. Sperling, M.; Xu, S.K.; Welz, B. Determination of chromium(III) and chromium(VI) in water using flow-injection online preconcentration with selective adsorption on activated alumina and flame atomic-absorption spectrometric detection. Anal. Chem. 1992, 64, 3101-3108. [CrossRef]

14. Zu, W.; Wang, Z. Ultra-trace determination of methylmercuy in seafood by atomic fluorescence spectrometry coupled with electrochemical cold vapor generation. J. Hazard. Mater. 2016, 304, 467-473. [CrossRef] [PubMed]

15. Armstrong, K.C.; Tatum, C.E.; Dansby-Sparks, R.N.; Chambers, J.Q.; Xue, Z.-L. Individual and simultaneous determination of lead, cadmium, and zinc by anodic stripping voltammetry at a bismuth bulk electrode. Talanta 2010, 82, 675-680. [CrossRef] [PubMed] 
16. Gómez-Navarro, C.; Meyer, J.C.; Sundaram, R.S.; Chuvilin, A.; Kurasch, S.; Burghard, M.; Kern, K.; Kaiser, U. Atomic structure of reduced graphene oxide. Nano Lett. 2010, 10, 1144-1148. [CrossRef] [PubMed]

17. Kochmann, S.; Hirsch, T.; Wolfbeis, O.S. Graphenes in chemical sensors and biosensors. TrAC Trends Anal. Chem. 2012, 39, 87-113. [CrossRef]

18. Zhu, Y.; Murali, S.; Cai, W.; Li, X.; Suk, J.W.; Potts, J.R.; Ruoff, R.S. Graphene and graphene oxide: Synthesis, properties, and applications. Adv. Mater. 2010, 22, 3906-3924. [CrossRef] [PubMed]

19. Geim, A.K.; Novoselov, K.S. The rise of graphene. Nat. Mater. 2007, 6, 183-191. [CrossRef] [PubMed]

20. Hwang, E.H.; Adam, S.; Das Sarma, S. Carrier transport in two-dimensional graphene layers. Phys. Rev. Lett. 2007, 98, 186806. [CrossRef] [PubMed]

21. Lee, P.M.; Wang, Z.; Liu, X.; Chen, Z.; Liu, E. Glassy carbon electrode modified by graphene-gold nanocomposite coating for detection of trace lead ions in acetate buffer solution. Thin Solid Films 2015, 584, 85-89. [CrossRef]

22. Xu, R.-X.; Yu, X.-Y.; Gao, C.; Jiang, Y.-J.; Han, D.-D.; Liu, J.-H.; Huang, X.-J. Non-conductive nanomaterial enhanced electrochemical response in stripping voltammetry: The use of nanostructured magnesium silicate hollow spheres for heavy metal ions detection. Anal. Chim. Acta 2013, 790, 31-38. [CrossRef] [PubMed]

23. Bagheri, H.; Afkhami, A.; Khoshsafar, H.; Rezaei, M.; Sabounchei, S.J.; Sarlakifar, M. Simultaneous electrochemical sensing of thallium, lead and mercury using a novel ionic liquid/graphene modified electrode. Anal. Chim. Acta 2015, 870, 56-66. [CrossRef] [PubMed]

24. Niu, X.; Yang, W.; Wang, G.; Ren, J.; Guo, H.; Gao, J. A novel electrochemical sensor of bisphenol a based on stacked graphene nanofibers/gold nanoparticles composite modified glassy carbon electrode. Electrochim. Acta 2013, 98, 167-175. [CrossRef]

25. Liang, Z.; Zhai, H.; Chen, Z.; Wang, H.; Wang, S.; Zhou, Q.; Huang, X. A simple, ultrasensitive sensor for gallic acid and uric acid based on gold microclusters/sulfonate functionalized graphene modified glassy carbon electrode. Sens. Actuators B Chem. 2016, 224, 915-925. [CrossRef]

26. Yang, J.; Deng, S.; Lei, J.; Ju, H.; Gunasekaran, S. Electrochemical synthesis of reduced graphene sheet-AuPd alloy nanoparticle composites for enzymatic biosensing. Biosens. Bioelectron. 2011, 29, 159-166. [CrossRef] [PubMed]

27. Shervedani, R.K.; Hatefi-Mehrjardi, A. Comparative electrochemical behavior of glucose oxidase covalently immobilized on mono-, di- and tetra-carboxylic acid functional Au-thiol SAMs via anhydride-derivatization route. Sens. Actuators B Chem. 2009, 137, 195-204. [CrossRef]

28. Ivandini, T.A.; Saepudin, E.; Wardah, H.; Dewangga, N.; Einaga, Y. Development of a biochemical oxygen demand sensor using gold-modified boron doped diamond electrodes. Anal. Chem. 2012, 84, 9825-9832. [CrossRef] [PubMed]

29. Zhang, Y.; Zhang, S.; Chung, T.-S. Nanometric graphene oxide framework membranes with enhanced heavy metal removal via nanofiltration. Environ. Sci. Technol. 2015, 49, 10235-10242. [CrossRef] [PubMed]

30. Gao, C.; Huang, X.-J. Voltammetric determination of mercury(II). TrAC Trends Anal. Chem. 2013, 51, 1-12. [CrossRef]

31. Argun, A.A.; Banks, A.M.; Merlen, G.; Tempelman, L.A.; Becker, M.F.; Schuelke, T.; Dweik, B.M. Highly sensitive detection of urinary cadmium to assess personal exposure. Anal. Chim. Acta 2013, 773, 45-51. [CrossRef] [PubMed]

32. Ma, X.; Chen, M. Electrochemical sensor based on graphene doped gold nanoparticles modified electrode for detection of diethylstilboestrol. Sens. Actuators B Chem. 2015, 215, 445-450. [CrossRef]

33. Serrano, N.; González-Calabuig, A.; del Valle, M. Crown ether-modified electrodes for the simultaneous stripping voltammetric determination of $\mathrm{Cd}(\mathrm{II}), \mathrm{Pb}(\mathrm{II})$ and $\mathrm{Cu}(\mathrm{II})$. Talanta 2015, 138, 130-137. [CrossRef] [PubMed]

34. Wu, K.; Hu, S.; Fei, J.; Bai, W. Mercury-free simultaneous determination of cadmium and lead at a glassy carbon electrode modified with multi-wall carbon nanotubes. Anal. Chim. Acta 2003, 489, 215-221. [CrossRef]

35. Cui, L.; Wu, J.; Ju, H. Nitrogen-doped porous carbon derived from metal-organic gel for electrochemical analysis of heavy-metal ion. ACS Appl. Mater. Interfaces 2014, 6, 16210-16216. [CrossRef] [PubMed]

36. Ruas de Souza, A.P.; Foster, C.W.; Kolliopoulos, A.V.; Bertotti, M.; Banks, C.E. Screen-printed back-to-back electroanalytical sensors: Heavy metal ion sensing. Analyst 2015, 140, 4130-4136. [CrossRef] [PubMed]

(C) 2016 by the authors; licensee MDPI, Basel, Switzerland. This article is an open access article distributed under the terms and conditions of the Creative Commons Attribution (CC-BY) license (http://creativecommons.org/licenses/by/4.0/). 